\title{
PATTERN OF INTOXICATION AMONG CHILDREN BELOW 14 YEARS ADMITTED TO A REFERRAL CENTER IN EGYPT
}

\author{
By \\ Arafa A. *, Galal N.** \\ FROM \\ *Lecturer of Toxicology, Cairo University \\ **Lecturer of Pediatrics, Cairo University
}

\begin{abstract}
Accidental Poisoning remains among the leading health hazards in young children despite frantic efforts of prevention worldwide. In Egypt, decreased awareness still prevails in most rural and semi urban areas. This study aims at reviewing the pattern of poisoning in children for better planning of preventive strategies. Methods: A review of the interval between the year 2005 through 2006 was done Retrospectively for 500 consecutive children aged 14 years or below presenting with accidental poisoning to NECTR(national Egyptian center for toxicological research) to assess pattern of intoxication among them . Our study included only subjects hospitalized at our center.

Results: There was a Male preponderance of $(60.6 \%)(n=303)$. Cases presenting between 2 and 5 years of age constituted the majority of cases $(56.6 \%)(n=283)$. Household products constituted $(55.4 \%)(\mathrm{n}=277)$, medicinal(therapeutic and non therapeutic) $(55.4 \%)(\mathrm{n}=277)$, medicinal(therapeutic and non therapeutic) drugs constituted $(28.2 \%)(n=141)$, food poisoning constituted $(7.6 \%)(n=38)$, animal bites or stings $(2.8 \%)(n=14)$ and poisoning due to unknown substances constituted $(6 \%)(n=30)$.
\end{abstract}


Conclusion: Accidental poisoning remains a significant problem to date in Egypt and needs spread of health awareness to minimize this preventable problem.

Key words: Acute Poisoning -Toddlers and Children-Household exposures.

\section{Introduction}

Accidental poisoning remains a global problem confronted in industrialized countries as well as developing countries in spite of new prevention strategies, along with improved management techniques. $(3,9,14,16)$. Among children, curiosity, limited knowledge, and developmental ability at certain age increase their poisoning rates. Special attention has been granted during the past two decades for child health in Egypt.

For developing countries, the problem is compounded by a number of unique situations, viz., economic priorities, and poverty which impose additional risk factors for poisoning. (11). The majority of intoxications in pre-school children occur at home whereas patterns, ingested substances, management and prophylaxis differ according to societies and cultures. Research aims at determination of current nature and level of preventive actions that parents take to avoid unintentional poisoning among toddlers .

Studies stated that clinicians should consider that the presence of some hazards may indicate an increased risk for home intoxications which stresses the need for behavioral modification. (13). Analytical understanding of the patterns in a community must precede planning of successful preventive campaigns. In Egypt medicines and pharmaceuticals are dispensed in ordinary ,easily accessible packages imposing a serious health hazard. Household maintenance and cleaning products involve the use of caustic substances as potash and kerosene probably because of economic factors as well as ignorance of hazards involved. Other factors involve not reading detergents' labels, using detergents' containers for food or beverage bottles for chemicals ${ }^{(1)}$. Studies showed that parents were more likely to store medicines more safely than cleaning products, and these products were most often stored unsafely in the kitchen, where children were left unattended (4). There is minimal knowledge of the dangers imposed by non pharmatheuticals chemicals involved in home care products. Environmental health was included as one of the four main objectives of the strategic Healthy Egyptians by 2010 Initiative and provision of safe environments for children starts at home. 


\section{Methods}

This study analyzed 500 consecutive children aged 14 years or below presenting to NECTR (National Egyptian Center of Toxicological Research of Cairo University) during the years 2005 and 2006. Cases were diagnosed as accidental poisoning. The sample consisted of 303 males and 197 females and ages ranged from less than 2 years to 14 years.

Blood samples were obtained to ana- lyze for detection of poisoning agents when the history was inexact or obscure. The following information was obtained whenever possible: age, sex; time of poisoning; duration of ingestion prior to medical attention; type of substance ingested; amount and formulation of the substance ingested; container details; history of the event; first aid performed; hospital management details; and outcome.

Data were analyzed using SPSS software.

\section{Results:}

Table (1):The incidence of different types of poisoning indifferent age groups

\begin{tabular}{|l|c|c|c|c|}
\hline & $\begin{array}{c}\text { Children } \\
>2 \text { years } \\
(\mathrm{n}=117)\end{array}$ & $\begin{array}{c}\text { Children } \\
\text { from2 -<5 } \\
\text { years } \\
(\mathrm{n}=283)\end{array}$ & $\begin{array}{c}\text { Children } \\
\text { from 5- } \\
<10 \text { years } \\
(\mathrm{n}=49)\end{array}$ & $\begin{array}{c}\text { Children } \\
\text { from10 -14 } \\
\text { years } \\
(\mathrm{n}=51)\end{array}$ \\
\hline Household products \& insecticides $(\mathrm{N}=277)$ & $82(70.08 \%)$ & $15(54.06 \%)$ & $19(38.77 \%)$ & $23(45.09 \%)$ \\
\hline Medicinal preparations( $\mathrm{N}=141)$ & $21(17.94 . \%)$ & $90(31.80 \%)$ & $10(20.40 \%)$ & $20(39.21 \%)$ \\
\hline Food poisoning $(\mathrm{N}=38)$ & $4(3.41 \%)$ & $15(5.30 \%)$ & $13(26.53 \%)$ & $6(11.76 \%)$ \\
\hline Insect bites $(\mathrm{N}=14)$ & & $7(2.47 \%)$ & $5(10.20 \%)$ & $2(3.92 \%)$ \\
\hline Unknown $(\mathrm{N}=30)$ & $10(8.54 \%)$ & $18(6.36 \%)$ & $2(4.08 \%)$ & \\
\hline TOTAL & $99.97 \%$ & $99.99 \%$ & $\% 99.98$ & $99.98 \%$ \\
\hline
\end{tabular}


Table 1 shows the incidence of different types of poisoning in different age groups.

There were 303 Males (60.6\%) and Females 197(39.4\%).Age was subdivided into brackets of below 2 years of age ,2-5 years of age ,5-10 years of age and older than 10 years. In the group of children below 2 years of ages household products (e.g. chlorine, , potash, kerosene , methanol, phenol and naphthalene) and insecticides(e.g. organophosphorus poisons, warfarin, toxaphene and zinc sulphide) caused the highest incidence of toxicity among children below 2 years old $(n=82)$ $70.08 \%$.

Ingested medicinal preparations (e.g. contraceptive pills , antihypertensives, digitalis, theophyline) come after household preparations in incidence of toxicity $(n=21) 17.94 \%$. Cases presenting with poisoning with unknown substance constituted $(\mathrm{n}=10)(8.54 \%)$, food poisoning caused $(n=4)(3.41 \%)$ of cases and no cases presented with animal bites and stings below 2 years old.

Children between 2-5 years old are mainly prone to household products and insecticide poisoning ( $\mathrm{n}=153)$ (54.6)\% this was followed by ingested medicinal preparations $(n=90)(31.80 \%)$, while poisoning with unknown substances was represented by 18 cases $(6.36 \%)$.Food poisoning cases at this age was represented by (15) cases $(5.30 \%)$ and animal bites and stings were represented by 7 cases $(2.47 \%)$.

In children between 5-10 years old the highest frequency of poisonings was highest due to household preparations $(n=19)$ (38.77\%) followed by ingested medicinal preparations $(n=10)(20.40 \%)$ then food poisoning which was represented by 13 cases $(26.53 \%)$.

Insect and snake bites were represented by 5 case (10.20\%).Poisoning with unknown substance was represented by 2 cases $(4.08 \%)$.

Children between 10- 14 years were mainly poisoned with household preparations $(n=23)(45.09 \%)$ this was followed by ingested medicinal preparations $(\mathrm{n}=20)$ $(39.21 \%)$ then food poisoning was represented by 6 cases $(11.76 \%)$ and insect and snake bites were represented by 2 cases only $(3.92 \%)$. 
Table(2) shows the incidence of different types of poisonings in relation to age

\begin{tabular}{|l|c|c|c|c|c|}
\hline & $\begin{array}{c}\text { Children } \\
<2 \text { years } \\
(\mathrm{n}=117)\end{array}$ & $\begin{array}{c}\text { Children } \\
\text { from2 - } \\
<5 \text { years } \\
(\mathrm{n}=283)\end{array}$ & $\begin{array}{c}\text { Children } \\
\text { from 5 - } \\
<10 \text { years } \\
(\mathrm{n}=49)\end{array}$ & $\begin{array}{c}\text { Children } \\
\text { from10 -14 } \\
\text { years } \\
(\mathrm{n}=51)\end{array}$ & $\begin{array}{c}\text { ALL } \\
\text { AGES }\end{array}$ \\
\hline Household & 82 & 153 & 19 & 23 & 277 \\
products \& insecticides & $(29.60 \%)$ & $(55.23 \%)$ & $(6.85 \%)$ & $(8.30 \%)$ & $(100 \%)$ \\
$(\mathrm{N}=277)$ & 21 & 90 & 10 & 20 & 141 \\
\hline Medicinal preparations & $(14.89 \%)$ & $(63.82 \%)$ & $(7.09 \%)$ & $(14.18 \%)$ & $(100 \%)$ \\
$(\mathrm{N}=141)$ & 4 & 15 & 13 & 6 & 38 \\
\hline Food poisoning & $(10.52 \%)$ & $(39.47 \%)$ & $(34.21 \%)$ & $(15.78 \%)$ & $(100 \%)$ \\
$(\mathrm{N}=38)$ & & 7 & 5 & 2 & 14 \\
\hline Insect bites & 10 & 18 & 2 & $(14.28 \%)$ & $(100 \%)$ \\
$(\mathrm{N}=14)$ & $(33.33 \%)$ & $(60 \%)$ & $(6.66 \%)$ & & 30 \\
\hline Unknown & & $(50 \%)$ & $(35.71 \%)$ & $(100 \%)$ \\
\hline$(\mathrm{N}=30)$ & & & & & \\
\hline
\end{tabular}

We can observe from this table that $(55.23 \%)$ of cases poisoned with household preparations occurred between 2 to 5 years old ,this is followed by (29.60\%) in children below 2 years old, those above 10years old represent $(8.30 \%)$ of cases, and the least percent of cases occurred in children between 5 to 10 years old $(6.85 \%)$.
Intoxication by ingested medicinal preparations intoxication occurred mainly among children between 2 to 5 years old and this represents $(63.82 \%)$,children below 2 years old represent $(14.89 \%)$, this is followed by children above 10 years old who represent (14.18\%) of cases and at last children between 5 to10 years represent $(7.09 \%)$ of cases . 
Food poisoning cases represent ( $39.47 \%$ ), between 2 to 5 years old, children between 5-10 years old represent (34.2\%) of cases, $(15.7 \%)$ of cases were among children above 10 years old ,and children below 2 years old represent (10.5\%) of cases. Among children between 2 to 5 years Insect and snake bites occurred in (50\%), (35.7\%) of cases were between 5 to 10 years old, and (14.3\%) of cases occurred in children above 10 years old.

Intoxication with unknown substances occurred mainly in the age between 2-5 years and represented $(60 \%)$, children below 2 years old represented (33.3\%) of cases and those between 5 to 10 years old were represented by $(6.66 \%)$.

The majority of children were brought directly from home to hospital (63\%); other cases were referred from other surrounding hospitals. Data about containers and amount ingested were not available in all cases.

In some cases pre-hospital first aid was offered to the child in the form of milk or the induction of vomiting based on folk beliefs. In 355 cases, children remained under observation in hospital for one day or less (71\%); 95 cases (19\%) stayed for 48-72 hours, 22 cases (4.4\%) stayed for more than 72 hours and 28 children (5.6\%) were referred to pediatric intensive care units .

In terms of hospital management, children were given specific antidotes in (41\%) of cases, gastric lavage was done for $(57 \%)$ of cases, intravenous fluids were given to $42 \%$ and charcoal orally was given to $67 \%$ ) of cases .

\section{Discussion-}

Poisoning remains a health hazard affecting children despite being primarily a preventable problem. Studies conducted worldwide show the existence of similar problems with different patterns and demographics. A Saudi Arabian study revealed that poisoning constituted $1.7 \%$ of total pediatric hospital admissions with drugs coming on top of the list especially over the counter medications ${ }^{(8)}$. As for the type of poisons involved, another study in Jeddah stated that drugs represented $47.84 \%$, food poisoning $19.19 \%$, chemicals $16.58 \%$, animal bites or stings $10.09 \%$, gases $2.52 \%$, and $3.78 \%$ of cases were of unknown origin (7).An Omani study with different demographics showed that the largest category (59.5\%) was animal bites and stings of which $25.4 \%$ were undiagnosed, $19.7 \%$ were scorpion stings, 
$7.6 \%$ were bee, spider or wasp stings and $6.8 \%$ were snake bites. Next highest (38.5\%) was ingestion of substances: $18.2 \%$ pharmaceuticals, $8.2 \%$ food and $4.7 \%$ household products $(3)$.

As for Iran, the type of agent involved in poisoning has been changing over time in children. The number of child poisoning due to hygienic preparations and cosmetics continued to increase over the last 10 year ${ }^{(10)}$. The United Arab Emirates(UAE), the pattern of poisoning was similar to that in western Europe and north America, with household chemicals and medicines predominating. Analgesics and antihistamines were most frequently ingested (6).

Our study showed that household exposures followed by medicinal preparations came first and second, respectively . The catchment area of the center covered Greater Cairo with a lot of semi urban areas where health awareness may be compromised.

Household products included chlorine and potash which are to the present time used for laundry and stored in ordinary beverage containers thus confusing children. Some products like kerosene and thinner were also prevalent poisons being used for cleaning purposes and household maintenance. Drugs and medicinal preparations are mostly still dispensed in ordinary non- childproof containers. Drug preparations included several items which include hazardous chemicals like oral contraceptive pills, which came on top of the list followed by analgesic antipyretics and non-steroidal anti- inflammatory drugs (paramol,aspirin,kentia,brufen), antihistami nic preparations, antibiotics, antihypertensives, and theophylline which are used only by adults which highlight the need for health awareness campaigns to minimize negligence.

There were only 38 cases of food poisoning $(7.6 \%)$ probably because they sought medical advice at neighboring Pediatric Hospitals with Gastroenterology clinics if the presentation mimicked an infectious cause .This result is different from Ghazawi et al study (1998) which stated that food poisoning represented $19.9 \%$ of cases of poisoning (7). In our study snake and scorpion bites were represented by 14 cases $(2.8 \%)$.

This small percentage is probably because of the more or less industrialized catchment area. Different demographics may be obtained in other desert related sites where those incidents are common. This was the case in Ghazawi et al. study 
(1998) which stated that the incidence of insect and snake bites was about $10.09 \%$. This may be due to the nature of the region where the study was done.(7) Poisoning was more prevalent among male children; this is in concordance with the study done by Ghazawi et al. (7) .This may refer to the more- risk taking behavior among male children. The highest proportion of cases was in those below 2 year old age bracket which is in agreement with many studies worldwide $(3,9,14,16)$.

This may be due to their developmental stage .The development of fine motor skills and increased mobility combined with their heightened curiosity, initiation of adult behavior and willingness to be separated from care givers place these children at greater risk ${ }^{(5)}$.

In this study we found a relation between the frequency of intoxication with certain poisons and age. The incidence of poisoning with household products and insecticides was high among children 5 years old or younger compared to those above this age.

Children 5 years old or younger represented $84.8 \%$ of all cases intoxicated with household products and insecticides which was a consequence of mistakes by mothers or other people taking care of the child who leave these products accessible to children who crawl everywhere.

As regard intoxication with medicinal preparations the highest incidence occurred among children between 2 to 5 years old $(63.8 \% \%)$ and this may be due to lack of education of care givers about the importance of safe storage of medicines .The lack of barriers between children and medicines or tablets not dispensed in foil or blister presents significant risk to children. This is in agreement with Dawson et al. who found that the 1 to 5 year old age group had the highest percentage of poisoning with ingested medicinal preparations (6).Also Coyte (1995) showed that $80 \%$ of all poisoning cases in children were due to ingesting substances that were not contained in child resistant containers $(5)$.

Children brought directly to hospital represented $63 \%$.This agrees with Dawson et al. (1997) who stated that $83 \%$ of children were brought directly from home to hospital (6).

Patients remaining under observation in hospital for one day or less represented 355 cases (71\%); 95 cases(19\%)stayed for 2 to 3 days ,and 22 cases (4.4\%)stayed for 
more than 3 days. However 28 cases $(5.6 \%)$ were referred to pediatric intensive care units.

These results are in keeping with Dawson et al. (1997)who stated that $75 \%$ of children remained under observation in hospital for one day or less (6).

In our study , $41 \%$ of cases were given specific antidotes, whereas gastric lavage was done for $57 \%$ of cases, intravenous fluids were given to $42 \%$ of cases and charcoal orally was given to $67 \%$ of cases .This is unlike Dawson et al. study where 2 cases only out of 134 cases (i.e.1.4\%)were given specific antidotes,33 cases $(24.6 \%)$ had gastric lavage done , 37 cases $(27.6 \%)$ took intra venous fluids and 6 cases $(4.4 \%)$ took charcoal orally ${ }^{(6)}$.

For our community, health education and instructions may be emphasized in visits for compulsory vaccination at maternal and child health units present allover the country or publicized via media programs. Home safety education in a clinical setting or at home especially with the provision of safety equipment like child - proof caps on all medicines and dangerous household products, and the availability of charcoal (universal antidote) for home use were found to be effective in increasing the range of safety practices $(12,15)$.

\section{Recommendations-}

Further prospective studies are needed to assess risk factors, document symptoms and study outcome and morbidity for individual poisons. Follow up after health education and improving sanitation is also needed to spot defects. Setting up of a follow up clinic for discharged cases is strongly recommended for better evaluation of outcome.

The establishment of nation wide network of communication with specialized Poison centers for consultation is also encouraged. Propagation of first aid information to primary care centers through unified guidelines will also help to improve the outcome.

\section{References:-}

1-Al-Nahedh NN and Mohammed AG. (2001) Accidental poisoning with household detergents. J Egypt Public Health Assoc.; 76(1-2):159-68.

2-Al-Wahaibi SS, Al-Riyami MM,and Al-Kharusi K.(2003) Profile of acute poisoning cases presenting to centres and hospitals in Oman SB, East Med. Health Journal ;9(5-6);944-54.

3- Andiran Nand Sarikayalar F.(2004) Pattern of acute poisonings in childhood in Ankara: what has changed in twenty years? Turk ;46(2):14752. Links 
4-Beirens TM-, van Beeck EF, Dekker R, Brug Jand Raat $H(2006)$ Unsafe storage of poisons in homes with toddlers. Accid Anal Prev. ; 38 (4):772-6.

5- Coyte,D.(1995) Childhood Poisoning for NZ Practice Nurse Communications Manager,Safekids News ;issue9.

6-Dawson K.P, Harron D, McGrath L, Amirlak I and Yassin A(1997)Accidental poisoning of children in the United Arab Emirates(UAE) East. Med. Health J., 3;38-42.

7- Ghaznawi H, Gamal-Eldin H and Khalil A (1989), Poisoning Problem In Jeddah Region. Annals of Saudi Med., 18: 5.

8-G. Ike Izuora (2001), A Seven-Year Review of Accidental Poisoning in Children at a military hospital in Hafr Al Batin, Saudi Arabia Ann Saudi Med ; 21(1-2):13-15.

9-Guyodol G and, Danel V.(2004) Childhood poisoning: data from the French Poison Control and Toxicovigilance Centers . Therapie.; 59(6):58993.

10-Hojatollah J, Seyed M, Seyed Shahram M and Fariba F (2002): Poisoning in children: a study of 1120 poisoned patients younger than 12 years at Loghman Hakeem Poison Control Center, Tehran, Iran, 2000-2001: The Internet Journal of
Pediatrics and Neonatology. V.2

11-Jamall IS and Davis B .(1991) Chemicals and environmentally caused diseases in developing countries. Infect Dis Clin North Am. Jun; 5 (2):365-75.

12-Kendrick D, Coupland C, Mulvaney C, Simpson J, Smith S, Sutton A Watson M, and Woods A. (2007) Home safety education and provision of safety equipment for injury prevention $\mathrm{Co}-$ chrane Database Syst Rev. Jan 24 ; (1).

13-LeBlanc JC, Pless IB, King WJ, Bawden H, Bernard-Bonnin $\mathrm{AC}$, Klassen $\mathrm{T}$ and Tenenbein $\mathrm{M}$ (2006):Home safety measures and the risk of unintentional injury among young children: a multicentre case-control study,CMAJ. 10; 175 (8):883-7.

14-Mucci Nlessi M, Binetti R,and Magliocchi MG (2006) Profile of acute poisoning in Italy. Analysis of the data reported by poison centers Ann Ist Super Sanita 42(3):268-76. 15-Schnitzer PG (2006): Prevention of unintentional childhood injuries :Am Fam Physician .1;74(11):1864-9.

16-Srivastava A, Peshin SS, Kaleekal T, and Gupta SK.(2005): An epidemiological study of poisoning cases reported to the National Poison Information Centre, All India Institute of Medical Sciences, New Delhi Hum Exp Toxicol.; 24 (6):279-85. 